\title{
BIBECHANA
}

A Multidisciplinary Journal of Science, Technology and Mathematics ISSN 2091-0762 (Print), 2382-5340 (Online)

Journal homepage: http://nepjol.info/index.php/BIBECHANA

Publisher: Research Council of Science and Technology, Biratnagar, Nepal

\section{Equatorial ionospheric plasma drifts velocities using radar observations}

\section{Narayan P. Chapagain}

Department of Physics, Patan Multiple Campus, Tribhuvan University, Lalitpur, Nepal

E-mail: npchapagain@gmail.com

Article history: Received 21 May, 2016; Accepted 2 August, 2016

DOI: http://dx.doi.org/10.3126/bibechana.v14i0.15405

This work is licensed under the Creative Commons CC BY-NC License.

https://creativecommons.org/licenses/by-nc/4.0/

\begin{abstract}
This study presents the experimental results of the equatorial ionospheric plasma drift zonal velocity obtained from Incoherent Scatter Radar (ISR) observations for 6 selective days in 2011 from Jicamarca, Peru. Our results indicate that the daytime drifts are westward with peak values mostly below $\sim 50 \mathrm{~m} / \mathrm{s}$, while the night time drifts velocities are eastward, with a maximum value up to $120 \mathrm{~m} / \mathrm{s}$ at around local midnight hours. The drift velocity decreases during post-midnight hours and starts to reverse westward in early morning hours. Our plasma drifts results are in good agreement with results from previous radar studies and other measurement techniques.
\end{abstract}

Keywords: Equatorial ionosphere, Plasma drift, F-region plasma, Incoherent scatter radar.

\section{Introduction}

The climatology and characteristics of low-latitude F-region plasma drift have been extensively studied over the past few decades using ground-based radar observations, optical measurements, ionosonde, and satellite observations $[1,2,3,4,5,6,7,8]$. The previous studies have shown that the night-time zonal plasma drifts in geomagnetically quiet days were eastward while plasma drift during the geomagnetic disturbance days are westward. Many of these studies have reported on the geomagnetic zonal motion of large-scale ionospheric depletions, or equatorial plasma bubbles (EPBs), and the small-scale irregularities $[9,10,11,12]$. Fejer et al. [12] reported the model results of zonal plasma drift velocity obtained from Jicamarca incoherent scatter (ISR) radar observations and they investigated that the zonal drifts velocities were westward during the day and eastward during the night-time period.

The majority of the information about plasma drifts at equatorial latitudes has come from observations at the Jicamarca Radio Observatory near Lima, Peru using incoherent scatter radar (ISR) at $50 \mathrm{MHz}$ [1, 3, 
12]. The primary goal of this on-going study is to address the zonal plasma drift velocity using the database available from Jicamarca ISR observations from the data recorded in 2011.

\section{Incoherent Scatter Radar (ISR)}

Radar techniques have been used since the beginning of the space age in the 1950 s to study the ionosphere [13]. Incoherent scatter radar is a very powerful ground-based remote sensing technique that can be used to measure many ionospheric parameters including density and temperature of the electrons and ions and line-of-sight ion flow velocity, as well as some of the properties and behaviour of the neutral atmosphere. It can also observe both sides of the peak electron density region simultaneously. It has a larger antenna relative to the radio wavelength and hence, it produces a narrow beam and achieves far better resolution. As incoherent radar scatter has to work with very weak signals, which requires a high power transmitter, a large antenna and the most sensitive receiver and sophisticated data processing available. This can be observed in very powerful radars such as Jicamarca Radio Observatory in Peru and Arecibo Observatory in Puerto Rico.

The physical basis of the incoherent radar technique is Thomson scattering in which the echo is the result of the scattering of electromagnetic energy radiated by the radar and reflected by electrons in the ionospheric plasma. Incoherent radars transmit a radar signal and receive a reflected echo from the ionosphere. ISRs' usually emit at a frequency of a few hundred $\mathrm{MHz}$ up to $1200 \mathrm{MHz}$ [14], which is much higher than the peak plasma frequency. Since the frequencies used by ISR are much higher than the plasma frequency, almost the entire transmitted signal passes through the ionosphere and out into space. Therefore, ISR can probe the ionosphere above the F-region peak. The transmitted signals are emitted in pulses so the distance of the echoing region (altitude) can be calculated from the delay time and the speed of light. However, there is a very small amount of the transmitted signal that gets reflected by the ionosphere and is received back to the radar. It is the spectrum of this received signal that contains the information about the ionospheric region being investigated. Overviews of this technique have been presented by several authors [14].

Thermal backscatter level is the source of the ISR echoes often used to determine ionospheric parameters. This method requires a minimum plasma density in the scattering volume determined by the system noise, antenna size, transmitter power, integration time etc. For the Jicamarca radio observatory, this

minimum is $\sim 10^{4} \mathrm{~cm}^{-3}$. This limitation usually prohibits measurements at night in the altitude range below the F peak.

\section{Measurement Techniques}

The Jicamarca Radio Observatory (JRO) is in the equatorial region of the western hemisphere and was established in 1961 at Lima, Peru $\left(12^{\circ} \mathrm{S}, 76.9^{\circ} \mathrm{W}\right.$, dip latitude $\left.\sim 1^{\circ} \mathrm{N}\right)$. The basic procedure for measuring F region drifts at Jicamarca was described in detail by Woodman [1]. Here we have explained briefly that 
the large $50 \mathrm{MHz}$ antenna is split into two beams perpendicular to the geomagnetic field and pointed about $2.5^{\circ}$ to the east and $4.3^{\circ}$ to the west of vertical, giving a net split of about $6.8^{\circ}$. These line-of-sight drifts are combined to give the vertical and zonal drift components. The measurements were usually made from about 200 to $900 \mathrm{~km}$ with a resolution of about $15 \mathrm{~km}$, and an integration time of about $5 \mathrm{~min}$. The data used in this study correspond to averages near the F region peak (typically between about 300 and $500 \mathrm{~km}$ ), where they do not change much with altitude, and the signal-to-noise ratios are highest. Reliable drift measurements are not possible during periods of spread $\mathrm{F}$ occurrence over a large range of altitudes.

Figure 1 shows an example of radar echo measured by ISR from Jicamarca on September 14, 2005. The figure indicates three nicely developed plumes with quasi-periodic equatorial spread F (ESF) structure on its bottom. The altitudinal resolution was $25-40 \mathrm{~km}$ with an integration time of $5 \mathrm{~min}$. In this paper, we use extensive F-region ISR data from Jicamarca to investigate the night-time zonal drift velocities. These velocities were calculated at altitude range of $\sim 300-400 \mathrm{~km}$, where signal-to-noise ratio is large.

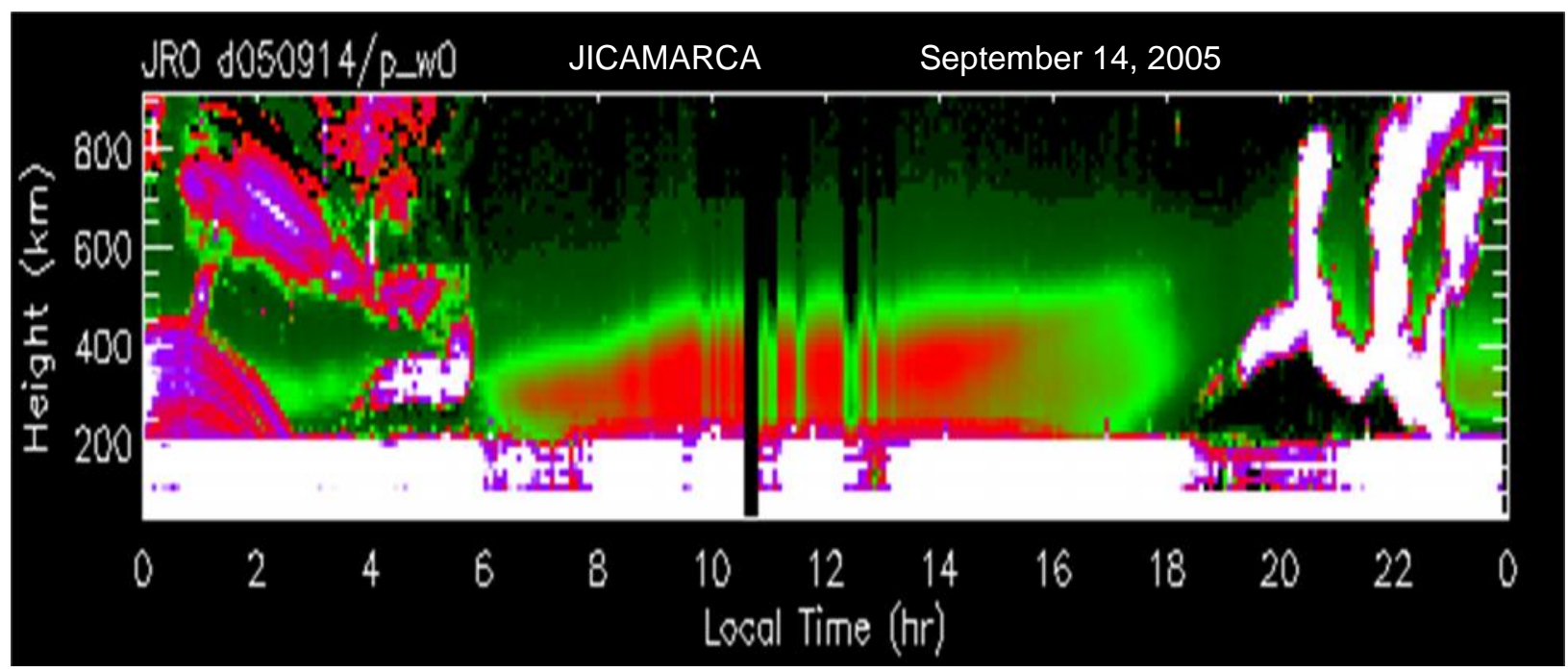

Fig. 1: An example of radar echo obtained from Jicamarca incoherent scatter radar observation on September 14, 2005.

In this study, we use selected days from data recorded by the Jicamarca incoherent scatter radar observations in 2011. Since the ISR requires high power transmitter, its running cost is very expensive. So the observations from ISR are recorded for a few days. The data presented in this paper are for 6 selective days from many observations, which give the overall trends of the plasma drifts velocity obtained over this region.

\section{Results and Discussion}

We have studied the diurnal variations of plasma drifts zonal velocities from Jicamarca ISR observations. Figure 1 shows the zonal plasma drift velocity as a function of local time (LT) over Jicamarca, Peru on 
01-02 and 03-04 August 2011. The solid curves represent the plasma drifts zonal velocities, while vertical bars denote the standard deviations in the measurement uncertainty at that time.
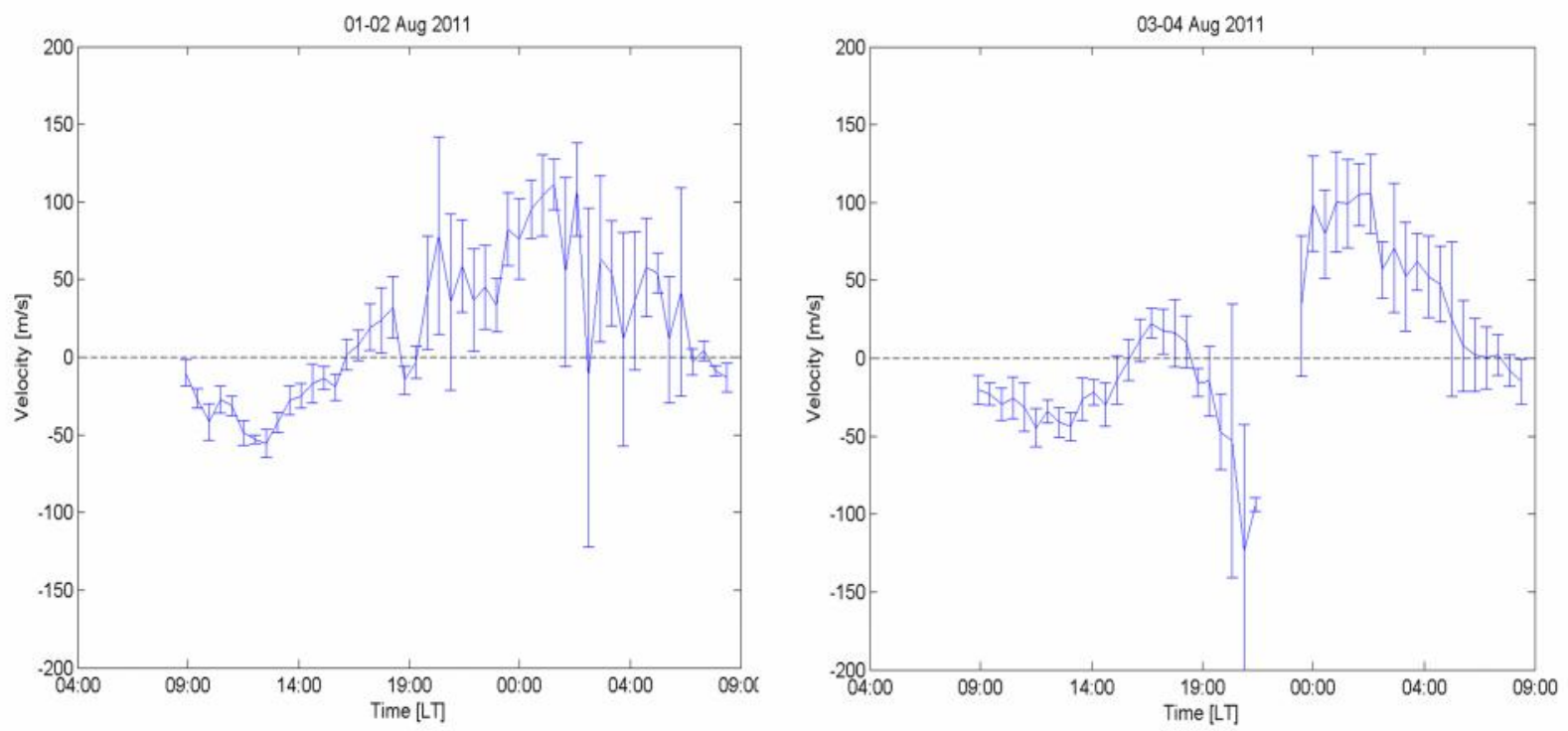

Fig. 2: Plasma drift zonal velocities using Incoherent Scatter Radar Observations obtained from Jicamarca Radar Observatory on 01-02 and 03-04 August 2011.

In the plot, positive values correspond to eastward drifts, while negative values denote the westward motions of the plasma drifts. In the first plot (August 01-02), initially, the drift velocity is almost zero at about 09:00 LT (day time) and then the drift motion is in westward, which increases as time progresses and then peaks to about $50 \mathrm{~m} / \mathrm{s}$ at around 12:00-13:00 LT. The drift velocity gradually decreases in magnitude and finally reverses eastward at $\sim 16: 00$ and $\sim$ 19:00 LT, around the sunset time. The eastward velocity gradually increases as the night progresses and finally becomes maximum value of about $120 \mathrm{~m} / \mathrm{s}$ at around local midnight (00:00 LT). The velocity then decreases in the post midnight hours and again starts to reverse westward in early morning (at around 07:00 LT).

On the second plot of Figure 2, the daytime plasma drift velocity is westward, which reverse eastward at around 15:00-16:00 LT. However, the data are discontinuous between 20:00 LT and local midnight, which does not represent actual trend of the plasma drift velocity. In the post midnight period, the results also show similar trends of variations of plasma drifts as plotted on August 01-02. In this case, the peak drift velocity is also $\sim 120 \mathrm{~m} / \mathrm{s}$ at just right after the local midnight. The drift velocity again reverses westward in the early morning hours at $\sim 07: 00 \mathrm{LT}$ with similar trends to the first plot.

Figure 3 also shows the local time variations of the average zonal drifts velocity on August 04-05 and 0708. Similar to previous plots, the daytime plasma drift velocity is westward, while the nighttime drift velocity is eastward. The magnitude of westward velocity is about $50 \mathrm{~m} / \mathrm{s}$ in the first plot and it is quiet 
large in the second plot increasing up to $\sim 100 \mathrm{~m} / \mathrm{s}$. In both plots, the magnitudes of eastward drifts velocities are larger than that of westward drifts. The trends of plasma drifts zonal velocities are similar to the other previous results reported by Fejer et al. and Chapagain et al. [3,4].
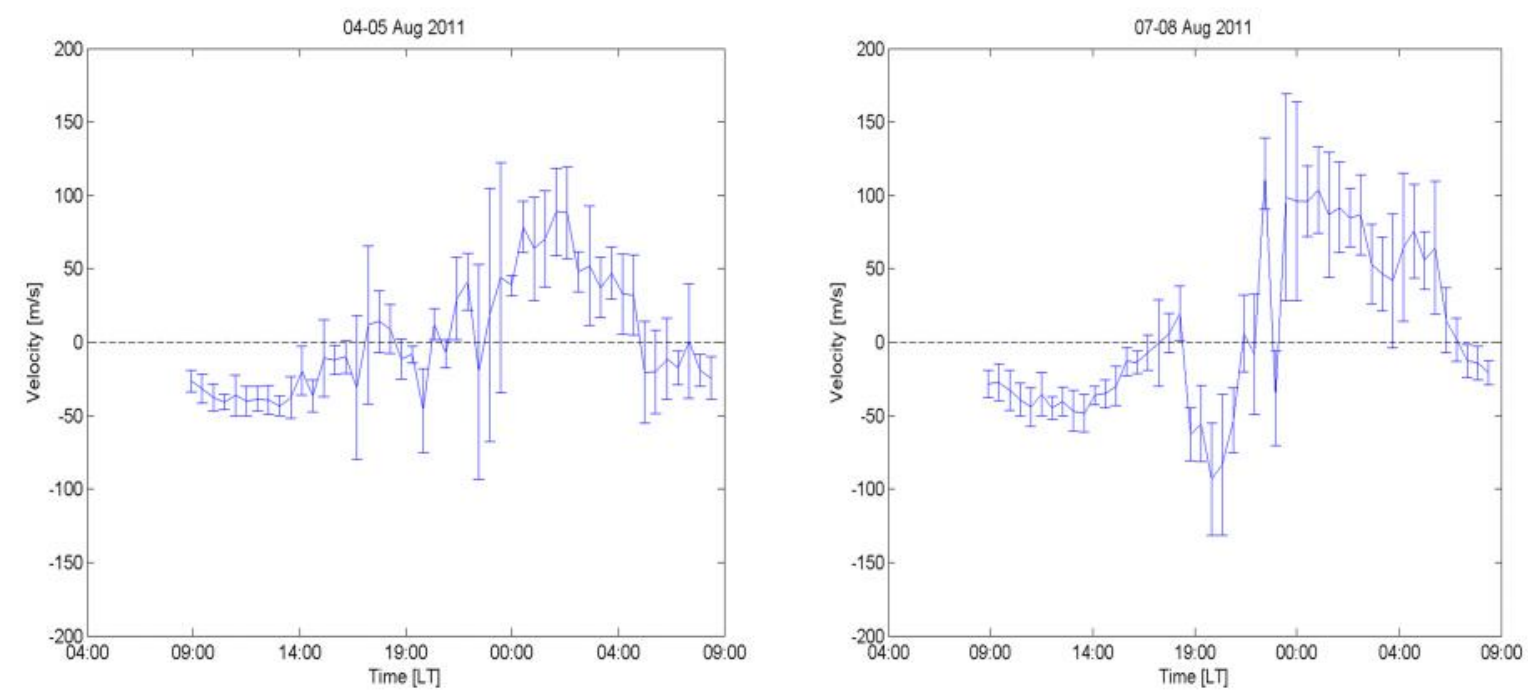

Fig. 3: Plasma drifts zonal velocities using Incoherent Scatter Radar Observations obtained from Jicamarca Radar Observatory on 04-05 and 07-08 August 2011.
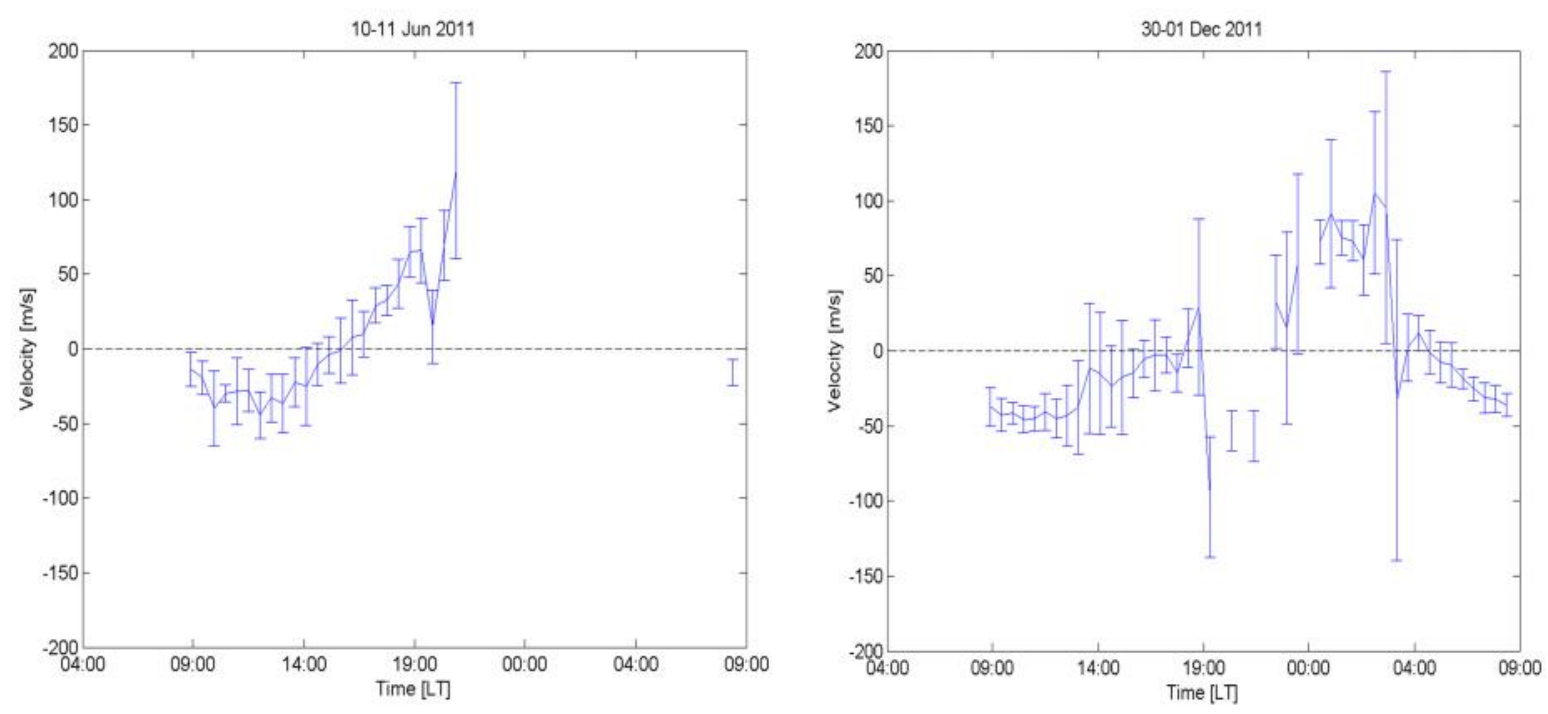

Fig. 4: Plasma drift velocities using Incoherent Scatter Radar Observations obtained from Jicamarca Radar Observatory on 10-11 June and 30 November - 01 December 2011.

Similarly, Figure 4 shows the plasma drifts zonal velocities on June 10-11 and November 30- December 01, 2011. Both plots show the westward motions during the day and eastward during night -time period in which the magnitudes of eastward motions are larger than that of the westward motions. In first plot, 
the data are not available after $\sim$ 22:00 LT, while in the second plot, the data are discontinuous around 19:00 LT to midnight hours. Similar trend of variations of the plasma drift velocities as a function of local time has been observed as in other plots.

The results presented above reveal a significant day-to-day variability in magnitudes of the plasma drift zonal velocities, however, the trends of the variations with the local time is similar. The plots as explained above (Figure 2- 4), show that daytime plasma drifts are westward, while the night-time drifts are eastward, which is consistent with the previous results $[3,4,12,15]$. Similarly, increase in the plasma drifts has been seen shortly after sunset (see in Figures 2-4) as the drift reverses from westward to eastward from the day to night transition. It is also noted that the eastward zonal drifts are much larger than the westward drifts. These results are good consistent with the previous experimental results [3] and the model results as well [12]. The zonal drifts have a large eastward peak (up to $120 \mathrm{~m} / \mathrm{s}$ ) near local midnight, and then gradually decrease during the post-midnight period. Fejer et al. [3] reported that Jicamarca plasma zonal drifts are westward during the day with typical values of about $40 \mathrm{~m} / \mathrm{s}$, and they do not change much with altitude, season, and solar activity. They also found that the night-time zonal drifts are eastward near the F -region peak with maximum values of about 100 and $150 \mathrm{~m} / \mathrm{s}$ near solar minimum and maximum, respectively. These drifts are largest at about 2100-2200 local time, and they decrease toward dawn. Our results are in moderate solar flux conditions, which is very good consist with the results reported by Fejer et al. [3] and Sobral et al. [16]. The daytime westward and night-time eastward zonal drifts are due to the upward vertical electric fields during the day and the downward fields during the night-time period, respectively $[17,18,19]$.

\section{Summary}

We have studied the trends of equatorial ionospheric plasma drifts zonal velocities using Jicamarca incoherent scatter observations for selective 6 days from many observations recorded in 2011. Our results indicate that the daytime drifts are westward with peak values mostly below $\sim 50 \mathrm{~m} / \mathrm{s}$. On the other hand, the night time drifts velocities are eastward, which gradually increases with the night progresses and finally becomes maximum value of about $120 \mathrm{~m} / \mathrm{s}$ at around local midnight hours. The velocity then decreases during post-midnight hours and again starts to reverse westward in dawn. Our plasma drifts results are in good agreement with results from previous radar studies and other measurement techniques. The day-time westward and night-time eastward zonal drifts are due to the development of upward vertical electric fields during the day time and the downward fields during the night-time period, respectively. The more research work needs to be done to investigate the actual physical process involved on these phenomena.

\section{Acknowledgement}

I would like to thank the team of the Jicamarca Radio Observatory, Peru for providing the data for this study. 
Narayan P. Chapagain/ BIBECHANA 14 (2017) 1-8 : RCOST p.7 (Online Publication: Dec., 2016)

\section{References}

[1] R. F. Woodman and C. LaHoz, J. Geophys. Res., 81 (1976) 5447-5466. http://dx.doi.org/10.1029/JA081i031p05447

[2] M. Mendillo and J. Baumgardner, J. Geophys. Res., 87 (1982) 7641-7652. http://dx.doi.org/10.1029//A087iA09p07641

[3] B. G. Fejer, E. R. de Paula, S. A. Gonzalez, and R. F. Woodman, J. Geophys. Res., 96 (A8) 13 (1991). 901-13,906.

http://dx.doi.org/10.1029/91JA01171

[4] N. P. Chapagain, M. J. Taylor, and J. V. Eccles, J. Geophys. Res., 116 (2011) A02301. http://dx.doi.org/10.1029/2010JA015958

[5] N. P. Chapagain Journal of Institute of Science and Technology, Tribhuvan University, 20(2) (2015) 84-89.

[6] J. H. A. Sobral, et al., J. Atmos. Terr. Phys., 73 (2011) 1520-1528.

http://dx.doi.org/10.1016/j.jastp.2010.11.031

[7] M. J. Taylor, Eccles J.V., LaBelle J. and. J.H. A Sobral, Geophys. Res. Lett., 24 (1997) 1699-1702. http://dx.doi.org/10.1029/97GL01207

[8] P.-D. Pautet, M. J. Taylor, N. P. Chapagain, H. Takahashi, A. F. Medeiros, F. T. Sao Sabbas, and D. C. Fritts, Ann. Geophys., 27 (2009) 2371-2381.

http://dx.doi.org/10.5194/angeo-27-2371-2009

[9] N. P. Chapagain, International Research Journal of Earth Sciences, 3(10) (2015) 7-13.

[10] E. R. dePaula, et al., J. Atmos. Sol.-Terr. Phys., 64(12) (2002) 1511 -1516.

http://dx.doi.org/10.1016/S1364-6826(02)00088-3

[11] N. P. Chapagain, M. J. Taylor, J. J. Makela, and T. M. Duly, J. Geophys. Res., 117(2012) A06316. http://dx.doi.org/10.1029/2012 JA 017750

[12] B. G. Fejer, J. R. Souza, A. S. Santos, and A. E. Costa Pereira, J. Geophysics. Res.,110 (2005). A12310, http://dx.doi.org/10.1029/2005JA011324

[13] W.E. Gordon, Incoherent scattering of radio waves by free electrons with applications to space exploration by radar, Proc. IRE, 46(1958) 1824.

http://dx.doi.org/10.1109/jrproc. 1958.286852

[14] M. C. Kelley, The Earth's Ionosphere: Plasma physics and electrodynamics, second edition. Academic Press, San Diego, California (2009).

[15] T. J. Immel, H. U. Frey, S. B. Mende, and E. Sagawa, Ann. Geophys., 22 (2004) 3099- 3107. http://dx.doi.org/10.5194/angeo-22-3099-2004

[16] J. H. A. Sobral et al., J. Geophys. Res., 114 (2009) A04309.

http://dx.doi.org/10.1029/2008JA013896 
Narayan P. Chapagain/ BIBECHANA 14 (2017) 1-8 : RCOST p.8 (Online Publication: Dec., 2016)

[17] J. V. Eccles, J. Geophys. Res., 103 (A11) (1998) 26699-26708.

http://dx.doi.org/10.1029/98JA02657

[18] J. V Eccles, N. Maynard, and G. Wilson, J. Geophys. Res.,104 (A12(1999) 28133-28143.

[19] H. Rishbeth, Journal of Atmospheric and Solar-Terrestrial Physics, 59 (1997) 1873-1880. http://dx.doi.org/10.1016/S1364-6826(97)00005-9 